\title{
SOCIO-CULTURAL CONTEXT, ADDRESS FORMS AND COMMUNICATIVE STYLES (A CASE STUDY OF BRITISH AND INDIAN ENGLISHES) ${ }^{1}$
}

\author{
Tatiana V. Larina \\ Peoples' Friendship University of Russia, Moscow, Russia \\ Neelakshi Suryanarayan \\ University of Delhi, Delhi, India \\ Yuliya B. Yuryeva \\ Peoples' Friendship University of Russia, Moscow, Russia
}

\begin{abstract}
The purpose of this study is to identify differences in the use of Address Forms for an unfamiliar addressee in British and Indian English and explain them through a sociocultural context. Given the fact that address forms are dependent on both situational and geographical parameters, and taking into account the rich cultural diversity of India, the study is limited to address forms used by residents of the two capital cities - London and Delhi. The material was collected through observations and questionnaires and was analysed with a comparative analysis (both quantitative and qualitative) and reference to the theory of cultural differences, intercultural pragmatics, politeness theory and the theory of culturally specific communication styles or communicative ethnic styles. For clarification of the results, the interview method was also used, attempting to establish the regularity with which the representatives of the given cultures use nominative address forms for an unfamiliar addressee, the choice of address forms for different age groups and gender and the sociocultural factors affecting the choice of address forms. The analysis of experimental data shows significant differences both in the choice of address forms and in their functioning, it convincingly demonstrates the influence of the Hindi language and local culture on the Indian version of the English language, on the communicative behaviour of Indian bilinguals in the given situation and their communication style in general.
\end{abstract}

Key words: address forms, sociocultural context, identity, bilingual, ethnocultural communication style, British English, Indian English, Hindi, linguistic experiment.

T.V., Suryanarayan N., Yuryeva Yu.B. Socio-Cultural Context, Address Forms and Communicative Styles (A Case Study of British and Indian Englishes). Vestnik Volgogradskogo gosudarstvennogo universiteta. Seriya 2. Yazykoznanie [Science Journal of Volgograd State University. Linguistics], 2019, vol. 18, no. 3, pp. 39-51. (in Russian). DOI: https://doi.org/10.15688/jvolsu2.2019.3.3 


\title{
Юлия Борисовна Юрьева
}

\author{
Российский университет дружбы народов, г. Москва, Россия
}

\begin{abstract}
Аннотация. Цель данного исследования - выявить различия в использовании форм обращения к незнакомому адресату в британском и индийском вариантах английского языка и объяснить их с опорой на социокультурный контекст. Учитывая зависимость форм обращения от ситуативных и географических параметров, а также принимая во внимание богатое культурное разнообразие Индии, авторы ограничились изучением обращений, которые используются жителями столиц - Лондона и Дели. Материал, полученный в ходе включенного наблюдения и анкетирования, был исследован с применением сопоставительного анализа (как количественного, так и качественного) и с опорой на теорию культурных различий, межкультурную прагматику, теории вежливости и культурно-специфичных стилей коммуникации, или коммуникативных этностилей. Для уточнения результатов применялся метод интервью, посредством которого были решены задачи по выявлению регулярности использования номинативных форм обращения к незнакомому адресату представителями изучаемых культур; набора форм обращения к незнакомым людям разного возраста и пола; социокультурных факторов, влияющих на выбор форм обращения. Проведенный анализ экспериментальных данных показал существенные различия в наборе форм обращения, их функционировании, убедительно продемонстрировал влияние языка и культуры хинди на индийский вариант английского языка, коммуникативное поведение индийских билингвов в рассмотренной ситуации, а также стиль их коммуникации.
\end{abstract}

Ключевые слова: формы обращения, социокультурный контекст, идентичность, билингв, этнокультурный стиль коммуникации, британский английский, индийский английский, хинди, лингвистический эксперимент.

Цитирование. Ларина Т. В., Сурьянараян Н., Юрьева Ю. Б. Социокультурный контекст, формы обращения и стили коммуникации (на примере британского и индийского вариантов английского языка) // Вестник Волгоградского государственного университета. Серия 2, Языкознание. - 2019. - Т. 18, № 3. - C. 39-51. - DOI: https://doi.org/10.15688/jvolsu2.2019.3.3

\section{Введение}

Формы обращения (далее - ФО) являются важным исследовательским объектом социолингвистики и социокогнитивной лингвистики, поскольку они демонстрируют то, как общественные отношения и основанные на них ценности отражены в сознании, социальных категориях, лексической системе языка и этикете общения. Другими словами, ФО - это свидетельства взаимосвязи языка, культуры, менталитета и коммуникации.

ФО представлены различными единицами, среди которых ученые выделяют местоименные формы 2-го лица, имена собственные, термины родства, титулы, прозвища и прилагательные [Fitch, 1998]. Их выбор и предпочтительность зависят от контекста в широком понимании этого термина.

ФО представляют собой важный и крайне чувствительный элемент социального взаимодействия. Через них проявляется как идентичность говорящего [Карасик, 2016; Larina, Ozyumenko, Kurteš, 2017], так и его отношение к собеседнику; они могут демонстриро- вать равенство или неравенство, уважение или неуважение, симпатию или антипатию, близость или отчужденность, любовь или враждебность и т. д. Выбор определяется различными аспектами социального, ситуативного и эмоционального контекста: возрастом, полом, статусом, уровнем близости, физическим и эмоциональным состоянием и др. Для успешного общения важно выбрать правильную ФО в соответствии с контекстом, намерением говорящего и ожиданиями собеседника. В условиях межкультурной коммуникации ситуация выбора ФО становится более сложной, чем при общении в рамках одной культуры, поскольку зависит еще и от социокультурного контекста. Как отмечает И. Кечкеш, «язык отражает ранее известную реальность, но он готов изменяться, как этого требуют социально-культурные факторы» [Кечкеш, 2014, с. 11]. Исследователь выделяет два типа контекстов, в которых проявляется знание внешнего мира: «актуальные, ситуативные, внеязыковые контексты и “старые”, предыдущие, прежние контексты, которые закодированы в словах и лингвистических единицах» [Кечкеш, 2014, с. 7]. 
Последние И. Кечкеш называет преконтекстами. Опираясь на эту классификацию, в качестве преконтекста, включающего весь прежний опыт и знания народа, которые закреплены в языке, можно рассматривать и культуру. В разных социокультурных контекстах предпочтение отдается разным категориям ФО. Например, если в западных культурах широко употребляются имена собственные, то во многих восточных культурах их использование имеет существенные ограничения и в ряде контекстов предпочтение отдается терминам родства [Которова, 2018; Anchimbe, 2011; Khalil, Larina, Suryanarayan, 2018; Larina, Khalil, 2018; Wierzbicka, 2016; Wong, 2006; и др.]. В каждой культуре есть своя система ФО и правил их употребления, которые отражают социокультурные различия, тип взаимоотношений и опираются на культурные ценности, понимание вежливого и невежливого поведения, что было показано в многочисленных исследованиях [Фирсова, 2013; Формановская, 1989; Afful, 2006; Aliakbari, Arman, 2013; Carreira, 2005; Chesnokova, 1996; Clyne, 2009; Clyne, Norrby, Warren, 2009; Fitch, 1998; Oyetade, 1995; и др.]. Несмотря на то что представители одного и того же культурного сообщества могут иметь индивидуальные особенности и предпочтения при обращении к адресату, существуют некоторые общие социокультурные правила, которым следует большинство в данном сообществе и которые отличают одну коммуникативную культуру от другой.

Убедительные доказательства определяющей роли социокультурного контекста при выборе ФО дают результаты сопоставительных исследований (см., например: [Смит, Ларина, 2003; Braun, 1988; Yuryeva, Rudakova, Larina, 2018; и др.]). Они подтверждают тезис о том, что «осмысление сложных взаимоотношений между дискурсом и обществом наиболее полно и естественно достигается при сочетании лингвистического и социального подходов» [Водак, 2006, с. 109]. Однако, на наш взгляд, особенно значимые результаты по установлению социокультурных факторов, влияющих на набор и выбор ФО, дает изучение функционирования ФО в различных вариантах одного и того же языка (см., например: [Hughson, 2009; Larina, Suryanarayan, 2013; Wong, 2006]). Они показывают, как заимство- ванный язык приспосабливается к потребностям и ценностям этнической культуры, а также как новая культура воздействует на родной язык.

В статье рассматриваются лексические и функционально-прагматические особенности ФО в двух вариантах английского языка - британском (далее - BrE) и индийском (далее IndE). Учитывая тот факт, что ФО и их функционирование в значительной степени зависят и от ситуативного, и от более широкого географического контекста, а также принимая во внимание богатое культурное разнообразие Индии, мы ограничились исследованием обращений к незнакомому адресату, которые используются жителями столиц - Лондона и Дели. Поскольку большинство представителей среднего класса Дели являются по меньшей мере билингвами, рассмотрим, как общепринятые традиции и нормы языка и культуры хинди влияют на выбор ФО носителями английского языка в Индии в ситуации «обращение к незнакомому адресату». Таким образом, цель нашего исследования - выявить различия в использовании ФО к незнакомому адресату в британском и индийском вариантах английского языка с учетом социокультурного контекста. Поскольку к важнейшим составляющим культуры относятся социокультурная организация общества и базирующиеся на ней ценности, мы принимаем во внимание такие параметры культуры, как социальная дистанция и дистанция власти (подробно о них см.: [Hofstede, 1984; 1991]), или горизонтальная и вертикальная дистанция, что позволит объяснить существенные различия в использовании ФО в британской и индийской лингвокультурах.

\section{Материал и методология}

Материал для анализа был собран с помощью методов этнографического наблюдения и анкетирования. Для уточнения результатов использовался метод интервью. Анкеты были составлены с учетом гендерных и возрастных различий информантов. С целью рассмотреть, как данные социальные факторы влияют на выбор и предпочтительность ФО, мы предложили респондентам 4 коммуникативные ситуации, в которых необходимо было обратиться к прохожему на улице и спро- 
сить о времени или направлении пути. В этих ситуациях предполагалось:

I. Обращение к мужчине старшего возраста.

II. Обращение к женщине старшего возраста.

III. Обращение к мужчине, равному по возрасту или младше.

IV. Обращение к женщине, равной по возрасту или младше.

В анкетировании приняли участие 100 респондентов: 50 говорящих на $\mathrm{BrE}$ и 50 индийских билингвов, говорящих на IndE и хинди. Bce они - представители среднего класса (студенты и преподаватели, а также служащие компаний) в возрасте от 18 до 60 лет. Всего было собрано 150 анкет и получено 600 реплик. Для того чтобы охарактеризовать влияние родной лингвокультуры на использование английского языка, мы попросили индийских билингвов заполнить по две анкеты - на английском языке и хинди.

В центре нашего внимания были следующие исследовательские вопросы:

1. С какой регулярностью представители рассматриваемых культур используют номинативные ФО?

2. Какие ФО употребляются по отношению к незнакомым адресатам разного возраста и пола?

3. Какое влияние на выбор ФО оказывают социокультурные факторы?

Сопоставительный анализ полученного материала (как количественный, так и качественный) осуществляется с опорой на теорию культурных различий [Hofstede, 1984; 1991], межкультурную прагматику [Kecskes, 2014; Wierzbicka, 2003], теорию вежливости [Brown, Levinson, 1987; Leech, 2014; Watts, 2003] и этнокультурных стилей коммуникации [Ларина, 2007; 2009; Gudykunst, Ting-Toomey, 1990; House, 2006; Larina, 2015].
В статье представлены предварительные результаты нашего исследования, которые раскрывают существенные сходства и различия, а также современные тенденции в использовании ФО в $\mathrm{BrE}$ и IndE.

\section{Результаты эксперимента}

Выявленные в результате работы различия касались лексического наполнения ФО, частотности их употребления и прагматического значения. Эти результаты подтвердили наши предварительные наблюдения и выводы, сделанные в ранее проведенных исследованиях [Larina, Suryanarayan, 2013], а также позволили установить некоторые новые особенности.

$\mathrm{B} \mathrm{BrE}$ номинативные ФО к незнакомому адресату имеют ограниченный характер. В нашем материале в среднем они были употреблены всего в 9 \% случаев (табл. 1). Наиболее частотной оказалась инициальная формула привлечения внимания Excuse me 'извините'. Она была использована в 77,6 \% проанализированных реплик. В некоторых случаях $(12,4$ \%) обращение начиналось с приветствия. Вариативность употребления номинативных ФО в рассмотренных ситуациях в BrE оказалась незначительной. Несколько чаще они употреблялись в адрес тех, кто старше: $12 \%$ - к мужчинам, $10 \%$ - к женщинам. По отношению к тем, кто одного возраста с адресантом и младше, ФО составили 8 и $6 \%$ соответственно. При обращении к старшим в основном употреблялись ФО sir / madam (в скобках после реплики указывается пол и возраст респондента, а также (факультативно) возраст адресата):

(1) Excuse me Sir! Would you show me how to get to the bus stop, please. (ж. / 34);

(2) Excuse me Madam, could you show me the way to the bus station, please. (м. / 38).

Таблица 1

Частотность употребления номинативных ФО в адрес незнакомого чел
носителями BrE, IndE и хинди, \%
\begin{tabular}{|l|c|c|c|}
\hline Ситуация обращения & BrE & IndE & Hindi \\
\hline К мужчине старшего возраста & 12 & 95 & 100 \\
\hline К женщине старшего возраста & 10 & 95 & 100 \\
\hline К мужчине, равному по возрасту или младше & 8 & 30 & 75 \\
\hline К женщине, равной по возрасту или младше & 6 & 20 & 45 \\
\hline Всего (в среднем) & $\mathbf{9}$ & $\mathbf{6 0}$ & $\mathbf{8 0}$ \\
\hline
\end{tabular}


В адрес равного по возрасту и младше британские респонденты использовали неформальные обращения, однако в очень незначительном количестве: buddy (4\%), mate (4\%), dear (4\%), luv (love) (2\%):

(3) Hey, buddy, could you show me the way to the bus stop, please. (м. / 38);

(4) Hello mate! Could you help me, please? (м. / 58);

(5) Excuse me dear, could you show me the way to the bus stop, please. (ж. / 41);

(6) Excuse me, luv! Would you show me how to get to the bus stop? Please. (м. / 51).

Как видно из примеров (1-6), информанты употребляли ФО только в сочетании с формулой привлечения внимания или приветствия. Самостоятельно она нигде не использовалась как инициальная. Это свидетельствует о том, что прежде, чем обратиться с запросом информации или просьбой, коммуниканты - носители британской культуры, говорящие на $\mathrm{BrE},-$ выбирают элементы фатической коммуникации, что позволяет сохранить некоторую дистанцию в общении.

В отличие от британских респондентов, представители индийской культуры, говорящие на английском языке (IndE), продемонстрировали явно выраженную тенденцию к употреблению номинативных ФО при обращении к незнакомым людям (в среднем - 60 \% всех высказываний). При этом 95 \% респондентов сочли необходимым их использование при обращении к старшим (как мужчинам, так и женщинам). Значительно реже они употреб- лялись при обращении к тем, кто младше: $30 \%$ - к мужчинам, $20 \%$ - к женщинам.

В качестве особенности исследуемых ФО можно рассматривать их разнообразие, которое проявляется при употреблении как английских, так и заимствованных из языка хинди обращений. Характерным отличием от $\mathrm{BrE}$ стало использование при обращении к незнакомым адресатам терминов родства (в среднем - $52 \%$ ). При этом вариативность их употребления незначительная: $55 \%$ - при обращении к старшим (мужчинам и женщинам в одинаковой пропорции), $50 \%$ - к равным по возрасту или младше. Важно подчеркнуть, что это были как английские термины родства (uncle, aunty), так и заимствованные из хинди (bhai 'брат', bhaiya 'старший брат', behen 'сестра', didi 'старшая сестра' и др.) (табл. 2). В половине случаев к ним прибавлялась заимствованная из хинди частица $j i$ (jee), выражающая особую почтительность и уважение: uncle ji, aunty ji, didi $j i$, behen ji и т. д. К обращению bhai 'брат' добавлялось слово sahib (saab, sahab, sahib), также имеющее значение почтительности: bhai sahib, bhaisaab:

(7) Bhai saab, is there a metro station nearby?

Уточним, что слово sahib (saab, sahab) сохранилось с колониальных времен, когда оно использовалось как уважительная ФО к белому человеку. В современном IndE, по нашим наблюдениям, его часто употребляют

Таблица 2

\section{Номинативные ФО в адрес незнакомого человека, используемые носителями BrE, IndE и хинди}

\begin{tabular}{|c|c|c|c|c|c|c|}
\hline \multirow{2}{*}{ Ситуация } & \multicolumn{2}{|r|}{$\mathrm{BrE}$} & \multicolumn{2}{|r|}{ IndE } & \multicolumn{2}{|r|}{ Hindi } \\
\hline & $\%$ & $\Phi 0$ & $\%$ & ФO & $\%$ & ФO \\
\hline $\begin{array}{l}\text { К мужчине старшего } \\
\text { возраста }\end{array}$ & 12 & sir, mate & 95 & $\begin{array}{l}\text { sir, uncle, uncle ji, } \\
\text { bhaiya, bhai saab, } \\
\text { bhaisahab }\end{array}$ & 100 & $\begin{array}{l}\text { sir, uncle, uncle ji, } \\
\text { bhaiya, bhaisahab, } \\
\text { bhai ji, chacha ji, kaka } \\
\text { ji, baaba ji, babu ji }\end{array}$ \\
\hline $\begin{array}{l}\text { К женщине старшего } \\
\text { возраста }\end{array}$ & 10 & madam & 95 & $\begin{array}{l}\text { madam, ma'am, old } \\
\text { lady, aunty, aunty ji, } \\
\text { mata ji, behen ji, didi, } \\
\text { didi ji }\end{array}$ & 100 & $\begin{array}{l}\text { madam, ma'am, aunty, } \\
\text { aunty ji, behen ji, di- } \\
\text { di ji, bhabi ji, mata ji, } \\
\text { chachi ji }\end{array}$ \\
\hline $\begin{array}{l}\text { К мужчине, равному по } \\
\text { возрасту или младше }\end{array}$ & 8 & mate & 30 & $\begin{array}{l}\text { buddy, yaar, bhai, } \\
\text { bhaisahab }\end{array}$ & 75 & $\begin{array}{l}\text { buddy, babu, yaar, dost, } \\
\text { uncle, uncle ji, bhai, } \\
\text { bhaiya, bhaisahab }\end{array}$ \\
\hline $\begin{array}{l}\text { К женщине, равной по } \\
\text { возрасту или младше }\end{array}$ & 6 & honey love & 20 & $\begin{array}{l}\text { ma'am, miss, } \\
\text { behen ji }\end{array}$ & 40 & ma'am, miss, behen ji \\
\hline
\end{tabular}


со словом bhai 'брат'. Кроме того, в нашем материале имеются случаи употребления этого слова в функции обращения в сочетании с названиями профессий: doctor sahib, engineer sahib.

Рассмотрим ФО в IndE в исследуемых нами ситуациях.

При обращении к старшему по возрасту мужчине, помимо sir, 55 \% респондентов использовали термин uncle. Отметим, что данное обращение употребляли информанты в возрасте от 17 до 53 лет. Оно оказалось предпочтительным по отношению к тем, кто значительно старше по возрасту:

(8) Uncle ji, could you please tell me the time? (53-летний профессор университета - пожилому мужчине).

В случае менее существенной разницы в возрасте, как прокомментировали наши информанты, предпочтение отдается обращениям bhaiya 'брат', bhai saab или bhaisahab 'уважаемый брат':

(9) Bhaiya, what is the time please?

Сходная тенденция прослеживается и при обращении к старшей по возрасту женщине. Здесь использовались как madam (или ma'am), так и термин родства aunty (55\% обращений). Некоторые информанты отметили, что в зависимости от разницы в возрасте наряду с aunty они употребляют также термины didi 'старшая сестра' или behen 'сестpa'. В качестве единичных случаев встретились mata ji 'уважаемая мама' и old lady, указывающие на существенную разницу в возрасте. Данные факты свидетельствуют о том, что возраст в индийской культуре - это ценность, а его подчеркивание - проявление уважения. Как и в первой ситуации, половина респондентов, употребляющих термины родства, добавляли к ним уважительную частицу $j i$ (aunty ji) или слово sahib (saab, saha):

(10) Aunty ji, could you tell me how to get to the metro station? (м. / 35 - к пожилой женщине);

(11) Didi ji, is there a market nearby for vegetables? (ж./ 50);

(12) Bhaisahab, is this bus going to the hospital? (м. / 30).
При обращении к тем, кто равен адресанту по возрасту или младше (ситуации III, IV), уменьшается как количество употреблений номинативных ФО в целом (хотя и незначительно), так и использование терминов родства. При обращении к мужчинам ФО применялись в $30 \%$ случаев, к женщинам - в $20 \%$. Тем не менее половину из ФО (по 50 \%) составили термины родства. В ситуации III это были bhai и bhaisahab, в ситуации VI behen ji. Помимо терминов родства, при обращении к женщине употреблялись английские обращения ma'am и miss. При обращении к мужчине использовалось заимствованное из хинди слово yaar 'друг' и неформальное английское обращение $b u d d y$.

Как видно из примеров (10-12), в IndE обращение может выступать инициальной репликой, в отличие от $\mathrm{BrE}$, где оно предваряется приветствием или формулой привлечения внимания Excuse me. При этом обращение с запросом информации или просьбой имеет прямой характер.

Результаты проведенного эксперимента продемонстрировали, что IndE находится под существенным влиянием языка и культуры хинди. В рассмотренных ситуациях оно проявилось как в частотности употребления номинативных ФО, так и в их наполняемости: половина обращений - это термины родства.

Кроме того, результаты показали обоюдное влияние языков (английского и хинди), а также значительное воздействие национальной культуры говорящих на их коммуникативное поведение независимо от того, на каком языке они говорят (см. табл. 1, 2). Двустороннее влияние проявляется в том, что не только ФО из языка хинди проникают в IndE, но и английские формы, как показал наш материал, также находят свое применение, когда собеседники говорят на хинди. При этом мы не утверждаем, что данное наблюдение имеет универсальный характер, поскольку, как уже отмечалось, информантами были представители среднего класса, проживающие в Дели. Очевидно, что в провинциальных городах и сельских районах влияние английского языка на хинди окажется менее выраженным, а возможно, и вовсе будет отсутствовать.

Что касается коммуникативных и функционально-прагматических особенностей, 
выявленных в ходе сопоставительного анализа, то среди важнейших из них можно выделить следующие:

1) говоря на языке хинди, индийские билингвы используют ФО с большей регулярностью, чем при общении на IndE;

2) при общении на хинди во всех анализируемых ситуациях термины родства употребляются в качестве ФО чаще, чем в IndE;

3 ) используемые в обращении на хинди термины родства разнообразны, они выражают узкую семантику и указывают на различия в возрасте и линии родства;

4) говоря на хинди, коммуниканты демонстрируют, с одной стороны, тенденцию к установлению статусной асимметрии даже при общении с равными, а с другой - тенденцию к сближению.

Как показали результаты эксперимента, говоря на хинди при обращении к старшему, независимо от пола адресата, $100 \%$ респондентов использовали номинативные ФО, большую часть которых (около 90 \%) составили термины родства. К тем, что встречались в IndE (bhaiya, bhaisahab, bhai ji 'старший брат, уважаемый брат' и didi ji, behen ji 'старшая сестра, уважаемая сестра', uncle, uncle ji, aunty, aunty ji) прибавились: babu ji 'уважаемый отец', baaba ji 'уважаемый дедушка', mata ji 'уважаемая мама', chacha ji, kaka ji 'уважаемый младший брат отца', chachi ji 'уважаемая жена папиного младшего брата', bhabi ji 'уважаемая жена брата'.

В обращениях к человеку, равному по возрасту или младше, адресант учитывает гендер адресата. Если при обращении к мужчине частотность номинативных ФО снизилась со 100 до 75 \%, то к женщине она упала до $45 \%$. Возможно, это объясняется тем, что в ситуациях публичного общения к женщинам принято относиться с особым уважением и любой знак фамильярности может быть неверно истолкован. В пользу данного предположения свидетельствует и то, что ФО к незнакомым женщинам более формальны, чем к мужчинам. В нашем материале такие обращения представлены либо английскими ma 'am и miss, либо словами из хинди behen 'сестра' с маркером вежливости $j i$ - behen ji 'уважаемая сестра'.

ФО в адрес незнакомых молодых мужчин оказались не только более частотными, но и более разнообразными, чем обращения к молодым женщинам. Значительную часть (63\%) составили термины родства (как английские, так и хинди). Показательным является тот факт, что при обращении к ровеснику или мужчине младшего возраста, помимо bhai, bhaiya 'брат', bhaisahab 'уважаемый брат', были использованы термины родства, называющие родственников старшего поколения (uncle ji ‘уважаемый дядя’, babu ji ‘уважаемый отец'), что говорит о широкой семантике данного термина. Меньшей частотностью характеризуется обращение уaаr 'друг', которое предпочли 33 \% информантов. Неформальное английское обращение $b u d d y$ встретилось всего 1 раз.

Анализ использования ФО на языке хинди позволяет более четко определить особенности культуры и культурных ценностей, которые влияют на коммуникативное поведение. Он свидетельствует о том, что в данном языке категории родства охватывают не только тех, кто связан семейными отношениями, но и более широкий круг людей или почти всех, с кем общается говорящий. Этот факт подтверждают данные словарей и работы других исследователей (см.: [Mehrotra, 1985, p. 43]). B «Longman-CIIL English-English-Hindi Dictionary» (URL: https://www.abebooks.com/ 9788131731314/ Longman-CIIL-English-EnglishHindi-Dictionary-Central-Institute-8131731316/plp) отмечаются широкие возможности использования терминов родства в адрес людей, не являющихся членами семьи:

- bhai sahab (or sahib), bhaiya - cтарший брат, старший брат друга, старший брат жены, каждый, кто старше по возрасту (elder man of the society);

- didi - старшая сестра, учительница, женщина старшего возраста (elderly woman of the society);

- kkaaka / chahchaa - младший брат отца (дядя), друг отца, отец друга, каждый, кто старше по возрасту (elderly man of the society);

- kaakii / chaahchii - жена папиного младшего брата (тетя), мать друга, жена папиного друга, женщина старшего возраста;

- bhabi - жена старшего брата, жена друга, пожилая замужняя женщина.

При употреблении указанных терминов в ситуации, не связанной с семейными отно- 
шениями, к ним обязательно добавляется маркер вежливости ji (jee): didi ji, kaka ji, chacha $j i$ и т. д.

\section{Обсуждение результатов эксперимента}

Результаты проведенного исследования продемонстрировали влияние социокультурного контекста на выбор и частотность употребления ФО даже в тех ситуациях, когда люди используют варианты одного и того же языка. При выборе ФО коммуниканты руководствуются своими культурными ценностями и нормами, пониманием вежливого поведения.

Для объяснения выявленных различий в употреблении ФО мы обратились к анализу социокультурного контекста, прежде всего к социокультурной организации общества и культурным ценностям. Такие социальные параметры, как горизонтальная и вертикальная дистанции между адресатами, были успешно использованы Дж. Личем при описании прагматического выбора ФО [Leech, 1983, p. 126]. Для межкультурного исследования мы находим эти параметры чрезвычайно важными [Leech, Larina, 2014, p. 24-25], поскольку они являются основными характеристиками культуры [Hofstede, 1984; 1991].

При рассмотрении британской и индийской культур в соответствии с указанными параметрами обнаруживаются существенные различия. Британская культура является крайне индивидуалистической, или я-ориентированной [Ларина, Озюменко, 2016; Larina, Ozyumenko, Kurteš, 2017], для нее характерна значительная горизонтальная и незначительная вертикальная дистанции. Следовательно, основные культурные ценности, которыми британцы руководствуются как в жизни, так и в коммуникативном поведении, - это дистанция (горизонтальные отношения) и равенство (вертикальные отношения). Индийская культура, напротив, является коллективистской. Она характеризуется незначительной горизонтальной дистанцией, мы-ориентированностью, но при этом значительной вертикальной дистанцией. Следовательно, важнейшие ценности - близость отношений (горизонтальная шкала), но в то же время их иерархия, то есть уважение к статусу и почтение к старшим (вертикальная шкала).
Указанные культурные различия позволяют объяснить зафиксированные нами коммуникативные особенности. Поскольку номинативные ФО являются маркером близости, они в незначительной степени используются в британской культуре, где в основе вежливости лежит соблюдение дистанции в общении. При обращении к незнакомому человеку предпочтение отдается нулевой ФО и формуле привлечения внимания Excuse me. Представляется вполне логичным также, что в культуре, где ценится дистанция в общении и семья является нуклеарной, термины родства в коммуникативных ситуациях, не связанных с семейными отношениями, не используются. Такие лексические единицы, как uncle, aunty, brother, sister и др., обозначают только родственников, более того, даже в рамках семейной коммуникации их употребление становится все менее регулярным.

Важной культурной ценностью британцев является равенство, они воздерживаются от указания на асимметрию в отношениях, даже когда она присутствует, что становится все более заметным в последнее время. Наше исследование подтверждает тот факт, что использование формальных обращений sir и madam значительно сократилось [Смит, Ларина, 2003; Hinton, 2006], неформальность в общении допускается все чаще и не нарушает норм вежливости. Названные особенности формируют британский стиль коммуникации, который применительно к рассмотренной ситуации можно назвать «анонимным» или «анонимно-эгалитарным» [Larina, Suryanarayan, 2013].

Для представителей индийской культуры, напротив, важно выразить близость к собеседнику, но в то же время подчеркнуть его статус. С этой целью они приспосабливают стиль коммуникации к своим коммуникативным потребностям. Поскольку английский язык не предоставляет носителям индийской культуры возможности для реализации в полной мере коммуникативных намерений, они активно прибегают к языку хинди, заимствуя из него необходимые ФО. Здесь мы видим яркий пример речевой аккомодации, когда индийские билингвы корректируют чужой им стиль речи, приспосабливая его для выражения своих ценностей, отношений и намерений. 
При этом они демонстрируют уникальную и чрезвычайно интересную особенность в одном и том же контексте применяют две противоположные стратегии. Для того, чтобы показать близость, индийские билингвы широко используют как английские термины родства (uncle и aunty), так и единицы из языка хинди (bhaiya, behen, didi и др.). Употребляя эти слова, они реализуют стратегию сближения, вовлеченности, утверждая, что смотрят на собеседника как на члена семьи, то есть включают его в свой ближний круг. Здесь мы наблюдаем яркое проявление мы-идентичности представителей индийской культуры, демонстрацию позитивной вежливости [Brown, Levinson, 1987], или вежливости сближения [Ларина, 2009]. В то же время, добавляя к термину родства частицу $j i$ или слово sahib, они выражают почтение к адресату и подчеркивают его статус: uncle ji 'уважаемый дядя', didi ji 'уважаемая старшая сестра'. В силу данных особенностей мы идентифицируем индийский стиль коммуникации как иерархически-солидарный (solidarity-hierarchical) или интимно-иерархический (kinship-hierarchical) [Larina, Suryanarayan, 2013].

\section{Заключение}

В ходе исследования были проанализированы ФО к незнакомому адресату и их функционирование в коммуникации на британском и индийском вариантах английского языка. Полученные данные позволили выявить существенные различия и определить основные тенденции. Они показали, что в BrE номинативные ФО используются крайне редко, предпочтение отдается нулевой ФО и формуле привлечения внимания Excuse me. B IndE, напротив, номинативные ФО в адрес незнакомого человека являются конвенциональными, при этом значительное место среди них занимают термины родства (как английские, так и заимствованные из языка хинди). Приведенные факты подтверждают справедливость слов А. Вежбицкой о необходимости изучения терминов родства (несмотря на противоположное мнение антропологов, связанное с принадлежностью этой группы лексики к прошлому) для получения представления о том, как носители многих языков понимают свой социальный мир [Wierzbicka, 2013, p. 303].

Результаты исследования подтвердили положение о том, что социокультурная реальность часто представлена в сознании людей в виде различных и не всегда совпадающих категорий, что влияет на коммуникативное поведение и предопределяет его. Используя термины родства при обращении к незнакомому человеку, представители индийской культуры выражают свои ценности - близость и в то же время почтение.

Наличие таких коммуникативных особенностей объясняется спецификой социокультурных контекстов, коммуникативных ценностей, различий в понимании вежливости и определяет вектор их влияния на британский и индийский стили коммуникации.

Представленные в статье существенные тенденции функционирования ФО в рассматриваемых вариантах английского языка могут быть уточнены при дальнейшем изучении ФО в аспекте социальных и гендерных факторов. Продолжение исследовательского проекта мы видим в расширении коммуникативных ситуаций и контекстов, а также анализе других вариантов английского языка.

\section{ПРИМЕЧАНИЕ}

${ }^{1}$ Публикация подготовлена при поддержке Программы РУДН «5-100».

The study was carried out in the framework of "5-100" RUDN Program.

Некоторые результаты исследования были представлены на конференции Languages, Nations, Cultures Pluricentric Languages in Context(s) (LNC 2019), Stockholm University, 22-24 May, 2019 и частично опубликованы в [Larina, Suryanarayan, 2013].

\section{СПИСОК ЛИТЕРАТУРЫ}

Водак Р., 2006. Взаимосвязь «дискурс - общество»: когнитивный подход к критическому дискурсанализу // Политическая лингвистика. Вып. 19. C. 107-116. URL: https://elibrary.ru/download/ elibrary_11671164_70394265.pdf.

Карасик В. И., 2016. Дискурсивное проявление личности // Вестник Российского университета дружбы народов. Серия: Лингвистика. Т. 20, № 4. C. 56-77.DOI: 10.22363/2312-9182-2016-20-4-56-77. 
Кечкеш И., 2014. Слово, контекст и коммуникативное значение // Вестник Российского университета дружбы народов. Серия: Лингвистика. № 1. C. 7-18.

Которова Е. Г., 2018. Анализ терминов родства с помощью Естественного Семантического Метаязыка: подход Анны Вежбицкой // Beстник Российского университета дружбы народов. Серия: Лингвистика. Т. 22, № 3. C. 701-710. DOI: 10.22363/2312-9182-2018-223-701-710.

Ларина Т. В., 2007. Этностилистика в ее коммуникативном аспекте // Известия Российской академии наук. Серия литературы и языка. Т. 66, № 3. C. 3-17.

Ларина Т. В., 2009. Категория вежливости и стиль коммуникации : Сопоставление английских и русских лингвокультурных традиций. М. : Языки слав. культур. 512 с.

Ларина Т. В., Озюменко В. И., 2016. Этническая идентичность и ее проявление в языке и коммуникации // Cuadernos de Rusística Española. Vol. 12. P. 57-68.

Смит С., Ларина Т. В., 2003. Обращение в английской коммуникативной культуре (в сопоставлении с русской) // Русистика. № 1. С. 79-91.

Фирсова Н. М., 2013. Испанский речевой этикет. М. : Либроком. 208 с.

Формановская Н. И., 1989. Речевой этикет и культура общения. М. : Высш. шк. 159 с.

Afful J. B. A., 2006. Address Terms among University Students in Ghana: A Case Study // Language and Intercultural Communication. Vol. 6, iss. 1. P. 76-91.

Aliakbari M., Arman T., 2008. The Realization of Address Terms in Modern Persian in Iran: A Sociolinguistic Study // Linguistik Online. Vol. 35, iss. 3. P. 3-12.

Anchimbe E. A., 2011. On Not Calling People by Their Names: Pragmatic Undertones of Sociocultural Relationships in a Postcolony // Journal of Pragmatics. Vol. 43, iss. 6. P. 1472-1483.

Braun F., 1988. Terms of Address: Problems of Patterns and Usage in Various Languages and Cultures. Berlin : Mouton de Gruyter. 374 p.

Brown P., Levinson S. D., 1987. Politeness: Some Universals in Language Usage. $17^{\text {th }}$ ed. Cambridge : Cambridge University Press. 358 p.

Carreira M. H. A., 2005. Politeness in Portugal: How to Address Others // Politeness in Europe / L. Hickey, M. Stewart (eds.). P. 306-316. (Multilingual Matters).

Chesnokova O., 1996. Dialogic Motivation of Spanish Forms of Address // Dialoganalyse VI. Referate der 6. Arbeitstangung. Teil 1. Prag: Max Niemeyer Verlag Tübingen. P. 487-491.
Clyne M., 2009. Address in Intercultural Communication Across Languages // Intercultural Pragmatics. Vol. 6, iss. 3. P. 395-409.

Clyne M., Norrby C., Warren J., 2009. Language and Human Relations: Style of Address in Contemporary Language. Cambridge : Cambridge University Press. 196 p.

Fitch K. L., 1998. Speaking Relationally: Culture, Communication, and Interpersonal Connection. N.Y. : The Guilford Press. 239 p.

Gudykunst W., Ting-Toomey S., 1990. Culture and Interpersonal Communication. Thousand Oaks : Sage Publications. 248 p.

Hinton S., 2006. Call Me Madam or the Lost Key Word // English Today. Vol. 22, iss. 2 (86). P. 45-46.

Hofstede G. H., 1984. Culture's Consequences: International Differences in Work-Related Values. Beverly Hills, CA : Sage Publications. 327 p.

Hofstede G. H., 1991. Cultures and Organizations: Software of the mind. L. ; N.Y. : McGraw-Hill. $306 \mathrm{p}$.

House J., 2006. Communicative styles in English and German // European Journal of English Studies. Vol. 10, iss. 3. P. 249-267.

Hughson J., 2009. Diversity and Changing Values in Address: Spanish Address Pronoun Usage in an Intercultural Immigrant Context. Frankfurt a/M : Peter Lang. 324 p.

Kecskes I., 2014. Intercultural Pragmatics. Oxford : Oxford University Press. 277 p.

Khalil A., Larina T., Suryanarayan N., 2018. Sociocultural Competence in Understanding Forms of Address: Case Study of Kinship Terms in Different Cultural Contexts // EDULEARN18 Proceedings : $10^{\text {th }}$ International Conference on Education and New Learning Technologies (Palma, Spain, 2-4 July, 2018). P. 3038-3045. DOI: 10.21125/edulearn.2018.0799.

Larina T., 2015. Culture-Specific Communicative Styles as a Framework for Interpreting Linguistic and Cultural Idiosyncrasies // International Review of Pragmatics. Vol. 7, iss. 2. P. 195-215. DOI: 10.1163/18773109-00702003.

Larina T., Khalil A., 2018. Arabic Forms of Address: Sociolinguistic Overview // The European Proceedings of Social and Behavioural Sciences EpSBS. Vol. XXXIX - WUT 2018: Word, Utterance, Text: Cognitive, Pragmatic and Cultural Aspects. P. 229-309. DOI: http://dx.doi. org/10.15405/epsbs.2018.04.02.44.

Larina T., Ozyumenko V., Kurteš S., 2017. I-Identity vs We-Identity in Language and Discourse: AngloSlavonic Perspectives // Lodz Papers in Pragmatics. Vol. 13, iss. 1. P. 109-128.

Larina T., Suryanarayan N., 2013. Madam or Aunty ji: Address Forms in British and Indian English as 
a Reflection of Culture and Cognition // Variation in Language and Language Use: Linguistic, Socio-Cultural and Cognitive Perspectives / M. Reif, J. A. Robinson, M. Pütz (eds.). Frankfurt a/M : Peter Lang. P. 190-217.

Leech G., 1983. Principles of Pragmatics. L. : Longman. $250 \mathrm{p}$.

Leech G., 2014. The Pragmatics of Politeness. Oxford : Oxford University Press. 343 p.

Leech G., Larina T., 2014. Politeness: West and East // Вестник Российского университета дружбы народов. Серия: Лингвистика. № 4. Р. 9-34.

Mehrotra R. R., 1985. Sociolinguistics in Hindi context. New Delhi : Oxford and IBH Publishing Company. P. 39-79.

Oyetade S. O., 1995. A Sociolinguistic Analysis of Address Forms in Yoruba // Language in Society. № 24. P. 515-535.

Watts R., 2003. Politeness. Oxford : Oxford University Press. 304 p.

Wierzbicka A., 2003. Cross-Cultural Pragmatics: The Semantics of Human Interaction. $2^{\text {nd }} \mathrm{ed}$. Berlin ; N.Y. : Mouton de Gruyter. 502 p.

Wierzbicka A., 2013. Kinship and Social Cognition in Australian Languages: Kayardild and Pitjantjatjara // Australian Journal of Linguistics. Vol. 33, iss. 3. P. 302-321. DOI: 10.1080/07268602.2013.846458.

Wierzbicka A., 2016. Back to 'Mother' and 'Father' Overcoming the Eurocentrism of Kinship Studies through Eight Lexical Universals // Current Anthropology. Vol. 57, no. 4. P. 408-429.

Wong J., 2006. Contextualizing Aunty in Singaporean English // World Englishes. Vol. 25, iss. 3/4. P. $451-466$.

Yuryeva J., Rudakova E., Larina T., 2018. Sociolinguistic and Sociocultural Features of Language Use: Forms of Address in British English and Spanish // EDULEARN18 Proceedings : $10^{\text {th }}$ International Conference on Education and New Learning Technologies (Palma, Spain, 2-4 July, 2018). P. 3046-3052. DOI: 10.21125/edulearn.2018.0800.

\section{REFERENCES}

Vodak R., 2006. Vzaimosvyaz «diskurs - obshchestvo»: kognitivnyy podkhod k kriticheskomu diskursanalizu [Mediation Between Discourse and Society: Assessing Cognitive Approaches in CDA]. Politicheskaya lingvistika [Political Linguistics Journal], iss. 19, pp. 107-116. URL: https://elibrary.ru/download/elibrary_ 11671164_70394265.pdf.

Karasik V.I., 2016. Diskursivnoe proyavlenie lichnosti [Discourse Manifestation of Personality].
Vestnik Rossiyskogo universiteta druzhby narodov. Seriya: Lingvistika [Russian Journal of Linguistics], vol. 20, no. 4, pp. 56-77. DOI: 10.22363/2312-9182-2016-20-4-56-77.

Kecskes I., 2014. Slovo, kontekst i kommunikativnoe znachenie [Word, Context and Communicative Meaning]. Vestnik Rossiyskogo universiteta druzhby narodov. Seriya: Lingvistika [Russian Journal of Linguistics], no. 1, pp. 7-18.

Kotorova E.G., 2018. Analiz terminov rodstva s pomoshchyu Estestvennogo Semanticheskogo Metayazyka: podkhod Anny Vezhbitskoy [Analysis of Kinship Terms Using Natural Semantic Metalanguage: Anna Wierzbicka's Approach]. Vestnik Rossiyskogo universiteta druzhby narodov. Seriya: Lingvistika [Russian Journal of Linguistics], vol. 22, no. 3, pp. 701-710. DOI: 10.22363/2312-9182-2018-223-701-710.

Larina T.V., 2007. Etnostilistika v ee kommunikativnom aspekte [Ethnostylistics in Its Communicative Aspect]. Izvestiya Rossiyskoy akademii nauk. Seriya literatury $i$ yazyka [Bulletin of the Russian Academy of Sciences: Studies in Language and Literature], vol. 66, no. 3, pp. 3-17.

Larina T.V., 2009. Kategoriya vezhlivosti $i$ stil kommunikatsii: Sopostavlenie angliyskikh $i$ russkikh lingvokulturnykh traditsiy [Category of Politeness and Communication Style: Comparison of English and Russian Linguistic and Cultural Traditions]. Moscow, Yazyki slavyanskikh kultur Publ., 512 p.

Larina T.V., Ozyumenko V., 2016. Etnicheskaya identichnost $\mathrm{i}$ ee proyavlenie $\mathrm{v}$ yazyke $\mathrm{i}$ kommunikatsii [Ethnic Identity in Language and Communication]. Cuadernos de Rusística Española, vol. 12, pp. 57-68.

Smit S., Larina T.V., 2003. Obrashchenie v angliyskoy kommunikativnoy kulture (v sopostavlenii s russkoy) [The Reference in the English Communicative Culture (In Comparison with Russian)]. Rusistika [Russian Language Studies], no. 1, pp. 79-91.

Firsova N.M., 2013. Ispanskiy rechevoy etiket [Spanish Speech Etiquette]. Moscow, Librokom Publ. 208 p.

Formanovskaya N.I., 1989. Rechevoy etiket i kultura obshcheniya [Speech Etiquette and Communication Culture]. Moscow, Vysshaya shkola. 159 p.

Afful J.B.A., 2006. Address Terms Among University Students in Ghana: A Case Study. Language and Intercultural Communication, vol. 6, iss. 1, pp. 76-91.

Aliakbari M., Arman T., 2008. The Realization of Address Terms in Modern Persian in Iran: 
a Sociolinguistic Study. Linguistik Online, Vol. 35, iss. 3, pp. 3-12.

Anchimbe E.A., 2011. On Not Calling People by Their Names: Pragmatic Undertones of Sociocultural Relationships in a Postcolony. Journal of Pragmatics, vol. 43, iss. 6, pp. 1472-1483.

Braun F., 1998. Terms of Address: Problems of Patterns and Usage in Various Languages and Cultures. Berlin, Mouton de Gruyter. 374 p.

Brown P., Levinson S.D., 1987. Politeness: Some Universals in Language Usage. Cambridge, Cambridge University Press. 358 p.

Carreira M.H.A., 2005. Politeness in Portugal: How to Address Others. Hickey L., Stewart M., eds. Politeness in Europe, pp. 306-316. (Multilingual Matters).

Chesnokova O., 1996. Dialogic Motivation of Spanish Forms of Address. Dialoganalyse VI. Referate der 6. Arbeitstangung. Teil 1. Prag, Max Niemeyer Verlag Tübingen, pp. 487-491.

Clyne M., 2009. Address in Intercultural Communication Across Languages. Intercultural Pragmatics, vol. 6, iss. 3, pp. 395-409.

Clyne M., Norrby C., Warren, J., 2009. Language and Human Relations: Style of Address in Contemporary Language. Cambridge, Cambridge University Press. 196 p.

Fitch K.L., 1998. Speaking Relationally: Culture, Communication, and Interpersonal Connection. New York, The Guilford Press. 239 p.

Gudykunst W., Ting-Toomey S., 1990. Culture and Interpersonal Communication. Sage Series in Interpersonal Communication. Thousand Oaks, Sage Publications. 248 p.

Hinton S., 2006. Call me Madam or the Lost Key Word. English Today, vol. 22, iss. 2 (86), pp. 45-46.

Hofstede G.H., 1984. Culture's Consequences: International Differences in Work-Related Values. Beverly Hills, CA, Sage Publications. $327 \mathrm{p}$.

Hofstede G.H., 1991. Cultures and Organizations: Software of the Mind. London, New York, McGraw-Hill. $306 \mathrm{p}$.

House J., 2006. Communicative Styles in English and German. European Journal of English Studies, vol. 10, iss. 3, pp. 249-267.

Hughson J., 2009. Diversity and Changing Values in Address: Spanish Address Pronoun Usage in an Intercultural Immigrant Context. Frankfurt am Mein, Peter Lang. 324 p.

Kecskes I., 2014. Intercultural Pragmatics. Oxford, Oxford University Press. 277p.

Khalil A., Larina T., Suryanarayan N., 2018. Sociocultural Competence in Understanding Forms of Address: Case Study of Kinship Terms in Different Cultural Contexts. EDULEARN18
Proceedings : $10^{\text {th }}$ International Conference on Education and New Learning Technologies (Palma, Spain, 2-4 July, 2018), pp. 3038-3045. DOI: 10.21125/edulearn.2018.0799.

Larina T., 2015. Culture-Specific Communicative Styles as a Framework for Interpreting Linguistic and Cultural Idiosyncrasies. International Review of Pragmatics, vol. 7, iss. 2, pp. 195-215. DOI: 10.1163/18773109-00702003.

Larina T., Khalil A., 2018. Arabic Forms of Address: Sociolinguistic Overview. The European Proceedings of Social and Behavioural Sciences EpSBS. Vol. XXXIX-WUT 2018: Word, Utterance, Text: Cognitive, Pragmatic and Cultural Aspects, pp. 229-309. DOI: http://dx.doi. org/10.15405/epsbs.2018.04.02.44.

Larina T., Ozyumenko V., Kurteš S., 2017. I-Identity vs We-Identity in Language and Discourse: AngloSlavonic Perspectives. Lodz Papers in Pragmatics, vol. 13, iss. 1, pp. 109-128.

Larina T., Suryanarayan N., 2013. Madam or Aunty ji: Address Forms in British and Indian English as a Reflection of Culture and Cognition. Reif M., Robinson J.A., Pütz M., eds. Variation in Language and Language Use: Linguistic, Socio-Cultural and Cognitive Perspectives Series. Frankfurt am Mein, Peter Lang, pp. 190-217.

Leech G. 1983. Principles of Pragmatics. London, Longman. $250 \mathrm{p}$.

Leech G., 2014. The Pragmatics of Politeness. Oxford, Oxford University Press. 343 p.

Leech G., Larina T., 2014. Politeness: West and East. Vestnik Rossiyskogo universiteta druzhby narodov. Seriya: Lingvistika [Russian Journal of Linguistics], no. 4, pp. 9-34.

Mehrotra R.R., 1985. Sociolinguistics in Hindi Context. New Delhi, Oxford and IBH Publishing Company, pp. 39-79.

Oyetade S.O., 1995. A Sociolinguistic Analysis of Address Forms in Yoruba. Language in Society, no. 24, pp. 515-535.

Watts R., 2003. Politeness. Oxford, Oxford University Press. 304 p.

Wierzbicka A., 2003. Cross-Cultural Pragmatics: The Semantics of Human Interaction. Berlin, New York, Mouton de Gruyter. 502 p.

Wierzbicka A., 2013. Kinship and Social Cognition in Australian Languages: Kayardild and Pitjantjatjara. Australian Journal of Linguistics, vol. 33, no. 3, 2013, pp. 302-321. DOI: 10.1080/ 07268602.2013.846458.

Wierzbicka A., 2016. Back to 'Mother 'and 'Father' Overcoming the Eurocentrism of Kinship Studies through Eight Lexical Universals. Current Anthropology, vol. 57, no. 4, pp. 408-429. 
Т.В. Ларина, Н. Сурьянараян, Ю.Б. Юрьева. Социокультурный контекст, ФО и стили коммуникации

Wong J., 2006. Contextualizing Aunty in Singaporean English. World Englishes, vol. 25, iss. 3/4, pp. 451- 466.

Yuryeva J., Rudakova E., Larina T., 2018. Sociolinguistic and Sociocultural Features of Language Use: Forms of Address in British
English and Spanish. EDULEARN18 Proceedings: 10th International Conference on Education and New Learning Technologies (Palma, Spain, 2-4 July, 2018), pp. 3046-3052. DOI: 10.21125/ edulearn.2018.0800.

\section{Information about the Authors}

Tatiana V. Larina, Doctor, Professor, Department of Foreign Languages, Peoples' Friendship University of Russia, Miklukho-Maklaya St., 10/2, 117198 Moscow, Russia, larina-tv@rudn.university, https://orcid.org/0000-0001-6167-455X

Neelakshi Suryanarayan, PhD (Philology), Professor, Head of the Department of Slavic and Finno-Ugorian Languages, University of Delhi, 110007 Delhi, India, neelakshi55@yahoo.co.in, https://orcid.org/0000-0002-6657-2533

Yuliya B. Yuryeva, Postgraduate Student, Department of Foreign Languages, Peoples' Friendship University of Russia, Miklukho-Maklaya St., 10/2, 117198 Moscow, Russia, yurevayb@gmail.com, https://orcid.org/0000-0002-7366-6669

\section{Информация об авторах}

Татьяна Викторовна Ларина, доктор филологических наук, профессор кафедры иностранных языков, Российский университет дружбы народов, ул. Миклухо-Маклая, 10/2, 117198 г. Москва, Россия, larina-tv@rudn.university, https://orcid.org/0000-0001-6167-455X

Нилакши Сурьянараян, $\mathrm{PhD}$, профессор, заведующая кафедрой славянских и финноугорских языков, Делийский университет, 110007 г. Дели, Индия, neelakshi55@yahoo.co.in, https://orcid.org/0000-0002-6657-2533

Юлия Борисовна Юрьева, аспирант кафедры иностранных языков, Российский университет дружбы народов, ул. Миклухо-Маклая, 10/2, 117198 г. Москва, Россия, yurevayb@gmail.com, https://orcid.org/0000-0002-7366-6669 